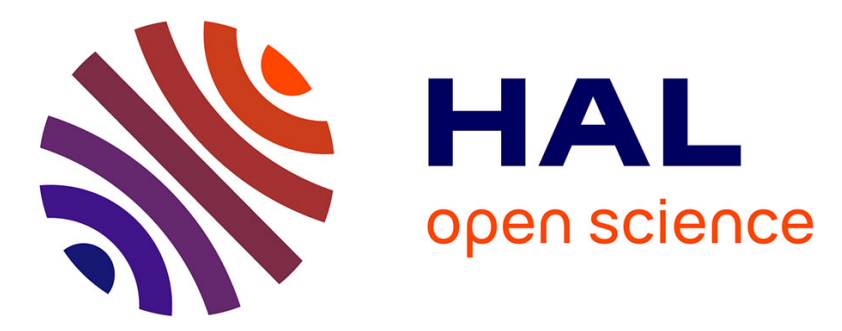

\title{
Development and validation of a numerical tool for simulating the surface temperature field and the infrared radiance rendering in an urban scene
}

\author{
N. Lalanne, J.C. Krapez, C. Le Niliot, X. Briottet, J. Pierro, L. Labarre
}

\section{- To cite this version:}

N. Lalanne, J.C. Krapez, C. Le Niliot, X. Briottet, J. Pierro, et al.. Development and validation of a numerical tool for simulating the surface temperature field and the infrared radiance rendering in an urban scene. 2015. hal-01111310

\author{
HAL Id: hal-01111310 \\ https://hal.science/hal-01111310
}

Preprint submitted on 30 Jan 2015

HAL is a multi-disciplinary open access archive for the deposit and dissemination of scientific research documents, whether they are published or not. The documents may come from teaching and research institutions in France or abroad, or from public or private research centers.
L'archive ouverte pluridisciplinaire HAL, est destinée au dépôt et à la diffusion de documents scientifiques de niveau recherche, publiés ou non, émanant des établissements d'enseignement et de recherche français ou étrangers, des laboratoires publics ou privés. 
Development and validation of a numerical tool for simulating the surface temperature field and the infrared radiance rendering in an urban scene

Nicolas Lalanne(1), Jean-Claude Krapez(1), Christophe Le Niliot(2), Xavier Briottet(3), Jean Pierro(1) and Luc Labarre(4)

(1) ONERA, The French Aerospace Lab,

13661 Salon de Provence, France

(2) IUSTI, 13453 Marseille cedex 13, France

(3) ONERA, The French Aerospace Lab,

31055 Toulouse cedex 4, France

(4) ONERA, The French Aerospace Lab,

91123 Palaiseau cedex, France

krapez@onera.fr 


\title{
Development and validation of a numerical tool for simulating the surface temperature field and the infrared radiance rendering in an urban scene
}

\begin{abstract}
A new simulator devoted to urban environment is presented. Its aims at generating the synthetic scene viewed by an infrared sensor after solving the direct heat transfer problem at the surface level. The software SOLENE (CERMA, Nantes) was coupled with two tools for realizing this task: SUSHI (Simulation in Urban Scene of Heat dIffusion) and MOHICANS. SUSHI purpose is to compute the external surface temperature of a building based on a $1 \mathrm{D}$ or a 2D heat transfer model. The 2D model is used in specific parts of the walls for simulating the impact of the thermal bridges on the façade temperature. Then, MOHICANS yields the infrared at-sensor radiance taking account reflections and atmosphere radiative contributions. A joined ground and airborne experiment has been done to validate this simulator. The results of this validation are presented showing a good adequacy between simulated and measured values for both temperature and infrared radiance.
\end{abstract}

Keywords: infrared thermography, building, urban, remote sensing, thermal bridge

\section{Introduction}

Human activity in urban area strongly influences the regional and local environment. For instance a practical consequence in terms of urban climatology is the development of urban heat islands. Urban climate is the result of heat and water flow processes between the urban surfaces and the environment. Infrared remote sensing is a powerful tool for measuring the thermal influence of these interactions on the urban surfaces at different spatial scales. As a matter of fact the infrared images acquired by airborne sensor inform about the thermal balance of urban components (buildings roofs and walls, roads, sidewalks,...) and, by merging all these effects at a larger scale, about the urban heat island [1]. Another application of infrared thermography is, at a higher resolution, the remote search for thermal disruptions on buildings envelope. This 
includes local flaws in the insulation layer, water ingress and thermal bridges [2][3][4]. The radiance images are however the result of complex phenomena both on the thermal level (i.e. how is a particular temperature field produced?) and on the radiation level (i.e. what is the link between previous temperature field and the recorded radiance image?); therefore a theoretical model is often necessary for interpreting these images. Later on this model is also necessary in the inversion process whose aim it to retrieve from the infrared images, first the true surface temperature field [5][6], then some thermal parameters of the buildings walls/roofs [7] [8][9][10], and the local heat losses [11] if they can ever be measured [12]. This model has to take into account the energy budgets at the different surfaces (roofs, roads, walls, etc.) including the radiative interactions in a spectrum extending from visible to far infrared. It should then solve the dynamic heat transfer problem in the solid materials of the urban scene at a scale compatible with the sensor resolution, which can be of the order of a tenth of a meter when the purpose is, for example, to detect insulation defects or to characterize the status of thermal bridges. Heat transfer through a wall may be multidimensional. Generally speaking, 2D transfer is observed at each corner of the building envelope (Lshape), and at thermal bridges like the floor/wall junctions (T-shape). 3D transfer is observed for example at a corner of a floor/wall junction. Finally, 1D transfer is observed over the building envelope far from previous thermal singularities. The computed surface temperature field has finally to be combined with the emissivity field in a radiative transfer module for getting the at-sensor infrared radiance field in the part of the $[3-15 \mu \mathrm{m}]$ spectrum corresponding to the IR sensor bandwidth.

The energy exchanges between cities and the atmosphere can be simulated at a scale between the mesoscale (whole city) and the building scale; such models are for example TEB [14] and SM2-U [15]. A second category of models includes the thermo- 
radiative models establishing the energy budget at a scale significantly lower than the building size (typically one meter or less). These models estimate all terms of the energy budget, in order to compute the temperature. A list of such models is described in table 1 . However they only compute surface temperature or the total radiance field in the direction of a virtual sensor obtained by applying the Stephan-Boltzmann law.

The thermo-radiative model SOLENE [21] solves the heat conduction problem in walls with a nodal method based on a preliminary evaluation of the radiative heat fluxes on the boundaries. A wall is modeled with one or two layers and discretized with five nodes at most. The consequence of this simplification is that the model does not correctly capture the behavior of complex walls, of heavy inertial materials, and of the ground [11]. For this reason we retained SOLENE only for computing the solar heating of the urban surfaces during one or diurnal cycles for alimenting our thermal software.

The temperature field can be obtained by analytical or numerical methods. The 1D thermal quadrupole is an analytical method particularly well suited for multilayer walls [34]. However its extension to multidimensional problems is restricted to simple geometries. In case of thermal bridge geometries, numerical methods are more appropriate such as the Boundary Element Method [35], the Finite Difference Method as used in EPS-r [36], the Finite Volume Method [37] [38] or the Finite Element Method [39]. Numerical methods would however be excessively time consuming when applied on an urban scene fragment. We thus propose a hybrid method combining the finite element method and the quadrupole method. The former is applied on walls and roofs in the vicinity of the thermal bridges and the latter is applied elsewhere on the buildings envelope and on the ground. 
Once the temperature field is known, the radiance images at the sensor level can be calculated. A radiative transfer code is required to simulate the multiple reflections between the surfaces of the scene and the atmosphere contributions. Atmospheric radiative transfer codes like Modtran [24] and MATISSE [25] are based on the radiative transfer equation and can calculate the spectral contributions of the atmosphere along the line of sight (transmission, self-emission, molecular/aerosol scattering...). They are however limited to a simplified geometry (plane or spherical ground). 3D radiative transfer codes were thus developed in order to take into account radiative interactions between $3 \mathrm{D}$ elements of a complex scene like urban scenes. In the infrared domain, DART [26] and TITAN [27] are such codes. DART is based on a 3D discretization of the urban scene and of the atmosphere in cubic voxels and the associated model DARTEB which allows to obtain the energy budget simulation and the 3D distribution of temperature uses the same thermal model as TEB. TITAN is an accurate urban radiative transfer tool for performing fine phenomenological analysis of remote sensing measurements [27] but it is limited to the MWIR/LWIR and supposes that the surface temperature is known. Thereafter, the new radiative transfer code MOHICANS (MOdélisation Hyperspectrale d'Images en entrée Capteur pour l'ANalyse et l'inversion du Signal - Model of at-sensor hyperspectral images for analysis and inversion of the signal) is proposed which results of the combination of AMARTIS [28] for the visible to $2.5 \mu \mathrm{m}$ spectral band and of TITAN for the 2.5 to $14 \mu \mathrm{m}$ spectral band. The interest of this code is to be able to simulate the signal of a hyperspectral sensor in the whole $[0.4-14 \mu m]$ spectral band.

As a consequence of what was presented before, we developed the thermal code SUSHI (Simulation in Urban Scene of Heat dIffusion) and coupled it with Sketchup, SOLENE and MOHICANS for getting a software tool able to simulate the whole 
thermal and radiative chain of processes at the origin of infrared radiance images of an urban scene in the thermal IR spectral domain [3-15 $\mu \mathrm{m}]$ and at a decimeter resolution. The numerical tool we developed is aimed at simulating the dynamic thermal behaviour of walls presenting areas where heat flow is either 1D or 2D. For getting a simulating IR image close to the one measured in a particular condition it is necessary to provide to the thermal software input data that finely describe the environment heat forcing (solar flux, atmospheric IR flux, internal and external convection). These external/internal conditions should be recorded for a sufficiently long period for enabling the dynamic thermal analysis to capture all thermal inertia effects.

In the first section we will describe the models, in particular SUSHI and MOHICANS. The first two points are common to all dimensional studies (1D or 2D) namely the hypothesis regarding the time evolution and the boundary conditions. In particular we will describe the modules used from SOLENE for computing the solar and infrared flux absorbed by each surface of the urban scene. Then we present the 1D thermal scheme based on the quadrupole method and the $2 \mathrm{D}$ scheme based on a FE method. The characteristics of the spectral model MOHICANS for the infrared rendering are finally recalled.

The second section is devoted to computation results. We will start by analyzing the validity of the hypothesis about the periodic character of the environment heat forcing. A short comparison of 1D SUSHI results with those obtained with SOLENE thermal model will then be presented. A detained sensitivity analysis regarding a typical 1D wall will allow sorting the thermal and radiative parameters according to their impact on the external surface temperature.

The third section will present some results obtained during the BATIR 2013 measurement campaign performed with two ground-based cameras and an airborne 
camera on two close buildings during the heating period for the validation of our numerical tool. The 1D temperature results will be compared to thermocouple readings and the 2D infrared radiance field will be compared with LWIR images recorded over a whole façade presenting different types of thermal bridges.

\section{Models description}

First we will describe the main aspects of the thermal code SUSHI and its coupling with SOLENE and MOHICANS. A series of programs are actually used as described in the chart in figure 1:

- SketchUp is used to build-up the 3D-scene and subdivide each wall in areas where heat flow is either $1 \mathrm{D}$ or $2 \mathrm{D}$;

- SOLENE is used to mesh each area, to compute the view factors and then the incident solar radiation after multiple reflections and shadow tracing at each time step;

- SUSHI (Simulation in Urban Scene of Heat dIffusion) is used to model the infrared radiation energy budget, the heat convection flux and then to solve the $1 \mathrm{D}$ and 2D heat transfer equation inside the walls and the soil elements for getting the surface temperature;

- MOHICANS is finally used to get the spectral infrared radiance incident to the sensor from the temperature field computed by SUSHI and from the atmosphere radiative parameters computed by MATISSE [25]. 


\section{Thermal model: SUSHI}

\section{Time evolution}

Temperature and fluxes are assumed to be periodic. This allows applying the Fourier transform which, thanks to the Fast Fourier Transform tool, leads to semi-analytical solutions and yields the results in a very short time. However, for simulating the façade temperatures at best, we have to consider real meteorological data for the input, i.e. solar radiation, air temperature, etc... These data can be seen as random variables; the $24 h$ periodic character is merely an approximation. When compared to the transient approach, for which an initial condition has to be specified (i.e. the initial temperature distribution in the walls and in the soil), the periodic approach relies on an initial condition which is actually the result of the repetition of an infinite number of periods of the input fluxes. For approaching the true aperiodic case, one should either reject the initial time far in the past for the transient approach, or take into account a long period for the periodic approach. In both cases it means recording meteorological data for a long duration before the time at which temperature has to be computed. We will call it the "pseudo-period". The question was then how to choose the pseudo-period aimed at representing the aperiodic phenomena. Of course it should be $24 h$ at least. If it is too short, let us say only $24 h$, the computed temperature would be in error due to fact that the atmospheric conditions were actually different any previous day. One should thus extend the duration of the pseudo-period. In this way, the first mismatch between the modelled atmospheric conditions (i.e. through the periodicity assumption) and the real atmospheric conditions would be rejected further in the past. The error on the computed temperature would then be lowered at the expense of a longer computation time. The optimal choice for the pseudo-period duration will be discussed later after completing the presentation of the thermal model. 


\section{Boundary conditions $(B C)$}

Each element of the mesh can exchange heat fluxes with the environment. In the general case, these fluxes are of convective and radiative nature. The radiative fluxes are subdivided into solar and infrared components. Both solar and infrared radiation can be partly absorbed and reflected by the surfaces. The solar radiation may be split into a direct and a diffuse component in order to give hourly shadow distribution. SOLENE is used to compute these solar components. In this software, the direct component follows the Perrin de Brichambaut formula, and the atmospheric diffuse component follows the "all weather model" of Perez et al. [29]. This provides spectral-integrated fluxes depending on place and hour, and on sky clearness and brightness for the diffuse component. The energy budget through multiple reflections is computed by the progressive refinement radiosity method [22] which first requires the calculation of the view factors between all surfaces of the scene including the "sky facets" (all urban surfaces are assumed to be Lambertian for the heat radiation calculation step). SOLENE however doesn't apply the progressive refinement radiosity method for evaluating the infrared radiative net fluxes, it rather considers a blackbody assumption. For avoiding this approximation we chose to perform a more rigorous infrared radiative exchange calculation by implementing the same progressive refinement radiosity method as for the solar radiation.

Let us now consider the convective flux on the external building surfaces. It may be modelled through a convective coefficient which depends on wind velocity and orientation, on air temperature, on local and global geometry, etc. A 3D fluid dynamics solver would provide a precise modelling of this coefficient [30] [31]. However, for keeping a reasonable computational time, we preferred to use one among the numerous 
empirical formulas giving the convective coefficient vs. wind velocity in the building thermal energy context [32]. The coefficient is thus time dependant: $h_{e x}(t)$.

The thermal balance at any facet of the outdoor building surface can be expressed as follows (for an inward oriented $\mathrm{z}$ axis):

$$
-\left.\lambda \frac{\partial T}{\partial z}\right|_{e x}=-h_{e x}(t)\left(T_{e x}-T_{e x}^{a i r}(t)\right)+\varphi_{V N I R}^{n e t}(t)+\varphi_{I R}^{n e t}\left(t, T_{e x}, T_{e n v}\right)
$$

It can be considered as a second order BC where the specified heat flux corresponds to the right-hand side of the equation. $T_{e x}^{a i r}$ is the external air temperature, $\varphi_{V N I R}^{n e t}$ is the net radiative flux in the visible and near infrared domain (i.e. the solar spectrum, $\lambda<3 \mu m)$ and $\varphi_{I R}^{\text {net }}$ is the net radiative flux in the thermal infrared domain ( $\lambda>3 \mu \mathrm{m})$; it depends on the atmospheric IR radiation, on the temperature of the surfaces exchanging radiation with it, all these environmental contributions being symbolically expressed through $T_{e n v}$, and on the temperature of the surface of interest itself, $T_{e x}$. This dependence is nonlinear which requires solving the problem through an iterative process. The time dependence of $h_{e x}(t)$ would also require iterations even though an alternative exists which avoids performing iterations but requires more involved algebra [33].

For speeding up the iterative process, the second order BC can be replaced by a third order $\mathrm{BC}$ where the linear heat exchange is given an arbitrary constant value, let us call it the fictitious transfer coefficient $h_{f i c}$. The BC now expresses as:

$$
-\left.\lambda \frac{\partial T}{\partial z}\right|_{e x}=-h_{f i c}\left(T_{e x}(t)-T_{s a}(t)\right)
$$


where $T_{s a}(t)$ corresponds to a modified sol-air temperature defined by:

$$
T_{s a}(t)=T_{e x}(t)+\frac{1}{h_{f i c}}\left[-h_{e x}(t)\left(T_{e x}-T_{e x}^{a i r}(t)\right)+\varphi_{V N I R}^{n e t}(t)+\varphi_{I R}^{n e t}\left(t, T_{e x}, T_{e n v}\right)\right]
$$

In other words, the thermal excitation associated with the $3^{\text {rd }}$ order $\mathrm{BC}$ is:

$$
-\Delta h_{e x}(t) T_{e x}+h_{e x}(t) T_{e x}^{a i r}(t)+\varphi_{V N I R}^{n e t}(t)+\varphi_{I R}^{n e t}\left(t, T_{e x}, T_{e n v}\right)
$$

where $\Delta h_{e x}(t)=h_{e x}(t)-h_{f i c}$.

A first iterative process identified by (1) in figure 2 is implemented by updating only the pseudo-convective flux term $\Delta h_{e x}(t) T_{e x}$. When a first convergence criterion is reached, the radiative flux term $\varphi_{I R}^{\text {net }}\left(t, T_{e x}, T_{e n v}\right)$ is updated (step (2) in figure 2) and the global iterative process is repeated until a second global convergence criterion is reached. The iterative process is split into two steps because updating the radiative flux terms is the most expensive. For the indoor BC, it is assumed that the environment is homogeneous and it is characterised by an indoor air temperature $T_{\text {in }}^{\text {air }}(t)$ and by a global constant radiato-convective transfer coefficient $h_{i n}$.

\section{D configuration}

As explained before, the 1D transfer model is used for the wall facets that are far from thermal singularities like façade corners, wall/floor junctions, ... . Its semi-infinite version is used for soil facets. The walls may be composed of many layers. It is assumed that each layer is homogeneous, isotropic with constant thermal properties. The thermal problem is solved by applying the quadrupole technique after performing a Fourier transform to the heat equation and to the boundary conditions [34]. The 
following backward transfer relation relates the vectors of temperature and conduction heat flux density at the external side and the internal side of the wall:

$$
\left(\begin{array}{l}
\tilde{T}_{e x} \\
\tilde{\varphi}_{e x}
\end{array}\right)=\mathbf{M}\left(\begin{array}{l}
\tilde{T}_{i n} \\
\tilde{\varphi}_{i n}
\end{array}\right)
$$

The tilde represents the Fourier transform, and $\mathbf{M}$ is the global quadrupole matrix obtained by multiplying the $N$ individual quadrupole matrices, $N$ being the number of layers of the wall [34]:

$$
\mathbf{M}=\left(\begin{array}{ll}
A & B \\
C & D
\end{array}\right)=\prod_{i=1}^{N}\left(\begin{array}{cc}
A_{i} & B_{i} \\
C_{i} & D_{i}
\end{array}\right)=\prod_{i=1}^{N}\left(\begin{array}{cc}
\cosh \left(\xi_{i} \sqrt{j \omega}\right) & \frac{1}{b_{i} \sqrt{j \omega}} \sinh \left(\xi_{i} \sqrt{j \omega}\right) \\
b_{i} \sqrt{j \omega} \sinh \left(\xi_{i} \sqrt{j \omega}\right) & \cosh \left(\xi_{i} \sqrt{j \omega}\right)
\end{array}\right)
$$

For each layer $i, \xi_{i}=l_{i} / \sqrt{a_{i}}$ is the square root of the diffusion time through the layer, $a_{i}$ is diffusivity, $l_{i}$ is thickness and $b_{i}$ is effusivity. $\omega$ is the pulsation and $j$ the imaginary variable $\sqrt{-1}$.

From eq. (5) one can express the external temperature as a function of external and internal net flux densities at iteration $k$ :

$$
\tilde{T}_{e x, k}=X \tilde{Q}_{e x, k}+Z \tilde{Q}_{i n}
$$

with the external transfer function

$$
X=\Lambda^{-1}\left(A^{\prime}+h_{i n} B^{\prime}\right)
$$

the internal transfer function:

$$
Z=\Lambda^{-1} \exp \left(-\left[\sum_{i=1}^{N} \xi_{\mathrm{i}}\right] \sqrt{j \omega}\right)
$$


the internal net flux density:

$$
\begin{gathered}
\tilde{Q}_{i n}=h_{i n} \tilde{T}_{i n}^{a i r} \\
\Lambda=h_{f i c} A^{\prime}+h_{f i c} h_{i n} B^{\prime}+C^{\prime}+h_{i n} D^{\prime}
\end{gathered}
$$

and the external net flux density is defined iteratively through:

$$
\tilde{Q}_{e x, k}=-T F\left(\Delta h_{e x} T_{e x, k-1}\right)+T F\left(h_{e x} T_{e x}^{a i r}\right)+\tilde{\varphi}_{V N I R}^{n e t}+\tilde{\varphi}_{I R, k-1}^{n e t}
$$

$A^{\prime}, B^{\prime}, C^{\prime}$ and $D^{\prime}$ are the reduced quadrupole coefficients, i.e. as obtained after factorizing each quadrupole matrix by the exponential of positive argument $\exp \left(\xi_{\mathrm{i}} \sqrt{j \omega}\right)$. This factorization and the subsequent simplifications in the transfer functions $X$ and $Z$ avoid round off errors otherwise occurring when the magnitude of the argument of the hyperbolic functions in eq. (6) reaches high levels ([40], [41]).

The temperature is then obtained after an inverse Fourier transform of $\tilde{T}_{e x, k}$ by applying the IFFTW algorithm [42]. The term $\Delta h_{e x} T_{e x, k-1}$ in eq. (12) can then be updated by $\Delta h_{e x} T_{e x, k}$ for a next iteration. Periodically the radiative term $\varphi_{I R, k-1}^{n e t}$ is also updated as described in figure 2.

\section{$2 D$ configuration}

When the one-dimensional assumption for heat conduction is not valid, like in the vicinity of thermal bridges, we substitute the $1 \mathrm{D}$ transfer functions $X$ and $Z$ by 2D transfer functions that are pre-calculated by a finite element method. For this purpose we use the software CAST3M. The objective is to get periodic transfer functions corresponding to the response of a thermal bridge when an elementary flux is applied over each one of the characteristic surfaces of the thermal bridge. Thus, when 
considering the symmetric L-shape in figure 3-left, a uniform flux is applied on surface $S_{1}$, then on surface $S_{3}$ (due to symmetry, the response is the same when the perturbation is applied on $S_{1}$ or on $S_{2}$ ). Similarly, for the symmetric T-shape in figure 3-right a uniform flux is first applied on $S_{1}$, then on $S_{2}$. In all cases, a unitary step heating is applied for a relatively long duration, typically several days. The transient response of the system is then subtracted to itself after a delay of one time step. This yields the system response to an elementary pulse. $\mathrm{N}$ replica of this response delayed by multiples of $24 \mathrm{~h}$ are then added together for getting the periodic response to an elementary pulse ( $\mathrm{N}$ should be sufficiently long for approaching the true periodic response). One is essentially interested in the external temperature induced by a uniform heat flux applied through periodic pulses on each of the surfaces $S_{l} \quad l=1, . .3$, i.e. the responses $G_{l}^{p}(x, t), \quad l=1, . .3$, where x runs on the surfaces $S_{1}$ and $S_{2}$ for the L-shape and on the surface $S_{1}$ for the T-shape (the responses $G_{l}^{p}(x, t)$ can be considered as integrated Green functions). The Fourier transform of these periodic responses $\tilde{G}_{l}^{p}\left(x, \omega_{k}\right), \quad l=1,3$ are then stored for future computations of the external temperature according to:

$$
\tilde{T}_{e x}\left(x, \omega_{k}\right)=\sum_{l=1}^{3} \tilde{G}_{l}^{p}\left(x, \omega_{k}\right) \cdot \tilde{Q}_{l}\left(\omega_{k}\right)
$$

where $\tilde{Q}_{l}\left(\omega_{k}\right)$ is the Fourier transform of the net heat flux density averaged over surface $S_{l}$ and $x$ is the position on the external surface. As before, for returning back to the temporal space an inverse fast Fourier transform is then performed with the IFFTW algorithm [42]. Present method involving integrated Green functions could be compared with the weighting factors method in [39] when 
conversely, the conduction flux is expressed as function of surface temperatures. The lateral size of the 2D model is chosen sufficiently high (typically $1 \mathrm{~m}$ from the thermal bridge centre) so that the response at its edges is very close to the $1 \mathrm{D}$ response. Then we retain only the $2 \mathrm{D}$ nodes where the response is significantly different from the 1D response.

\section{Spectral model: MOHICANS}

The software MOHICANS is a numerical tool developed at ONERA which aims at evaluating all radiative components contributing to the optical signal received by a multispectral or a hyperspectral sensor over a 3D scene. It is actually a fusion of two previously developed codes: AMARTIS [28] for the visible to near infrared range and TITAN [27] for the midwave to longwave infrared range. Both of them rely on atmospheric radiative contributions which are computed by the ONERA code MATISSE [25]. The spectral domain finally covers the 0.4 to $14 \mu \mathrm{m}$ range. MOHICANS is organized in four calculation steps: (i) computation of the sky irradiance hemisphere and the atmosphere transmission terms by calls to MATISSE, (ii) computation of geometrical terms corresponding to sun visibility, facet to facet visibility and facet to pixel visibility, (iii) computation of total irradiance, corresponding to the sum of solar direct irradiance, the atmosphere irradiance and the environment irradiance, (iv) computation of the radiance of the radiative flux reaching each pixel of the imaging sensor. A schematic of the radiative exchanges between two facets of a wall-soil angle is presented in figure 4.

\section{Computation results}

\section{Temporal configuration}

The first analysis concerns the validation of the time-periodic model. For simulating the temperature field over a one day time interval $\left[t_{0}-24, t_{0}\right]$ we assume that the radiative and 
convective fluxes are periodic with a pseudo-period $D$ and that their variations correspond to those observed experimentally during the time interval $\left[t_{0}-D, t_{0}\right]$ with $D=k x 24 h ; k \geq 1$. As explained earlier, due to weather changes, the experimental fluxes unavoidably show random variations. Despite an apparent $24 h$ periodicity they are not perfectly periodic. One way to circumvent this problem consists in taking a longer interval $D$, i.e. several days, and considering it as the new baseline for periodicity. This amounts to rejecting further to the past the unknown initial condition. As a matter of fact, the longer the pseudo-period $D$, the lower the error on temperature over the interval $\left[t_{0}-24, t_{0}\right]$ due to the wrong assumption about periodicity. The minimum number of days $k$ needed for getting an error lower than a specified value was determined by considering both an elementary part of a typical wall (see properties in table 2 ) with an albedo of 0.5 and an emissivity of 0.947 and a semi-infinite ground with an effusivity of 1000 and $2000 \mathrm{~J} \cdot \mathrm{s}^{-1 / 2} \cdot \mathrm{m}^{-2} \cdot \mathrm{K}^{-1}$ with same optical parameters. Both were submitted to the real atmospheric fluxes observed during the BATIR campaign for a horizontal surface (see last section). A long pseudo-period $D$ of 12 days was considered for getting the reference solution. Temperature was computed for progressively shorter pseudo-periods $D$ and compared to this reference. The maximum difference and the RMS error value over the day of interest (i.e. the last one) are plotted in figure 5 for the wall and for the ground. The relative difference in figure 6 is obtained by dividing previous errors by the day-night temperature difference observed during the last day, which is $13.3 \mathrm{~K}$ for the wall, $18.2 \mathrm{~K}$ for the low effusivity soil and $13.2 \mathrm{~K}$ for the high effusivity soil. These simulations show that a pseudo-period of one day is too short both for the wall and the soil temperature simulations: the maximum error is between 0.3 and $0.6 \mathrm{~K}$. A pseudoperiod of two days is long enough for the wall: both maximum error and RMS error are less than $0.01 \mathrm{~K}$. On the other side a pseudo-period of five days is necessary for both 
soils when setting the maximum error criterion to $0.1 \mathrm{~K}$. A soil with higher thermal inertia needs a longer pseudo-period for getting the same error. For the remaining we will perform the thermal simulations with a pseudo-period of $48 h$. The error is guaranteed to be low for the walls, but one has to be aware that it may be up to about $0.8 K$ (i.e. $6 \%$ of day-night amplitude) for high effusivity soils, depending on the environmental fluxes irregularity.

\section{Software validation and comparison with SOLENE}

Analytical validations of SUSHI model performed on basic configurations like a semiinfinite layer submitted to a sinusoidal boundary flux with or without convective losses showed a perfect match. A comparison with SOLENE results showed the limitations of this nodal model for simulating soils and very thick materials. Comparisons with SOLENE were also performed for standard walls: in the case of a single two layer slab both models give similar results. However, SUSHI permits to model walls made of more than two materials as opposed to SOLENE.

\section{Sensitivity analysis}

The sensitivity of the front temperature of a three layers wall was analysed with respect to the thermal, convective and radiative parameters. A series of 14 parameters was considered: the effusivity and the square root of the diffusion time of each layer (see table 2), the albedo and the emissivity of the external surface, the external and internal convective coefficients, the external and internal air temperature, and the VNIR and IR incident flux density. Their nominal values correspond to those observed for the façade of the building LC4 during the measurement campaign BATIR (see fig. 8).

We defined two groups of parameters, according to their time dependency. The external convective coefficient, the external and internal air temperature and the 
incident radiative flux densities all vary with time. For static parameters $\beta$ we introduced, as usual, a specific relative variation with respect to their reference value $\beta_{\text {ref }}$ according to: $\Delta \beta=K \beta_{\text {ref }}$ with $|K|<<1$. For time-dependent parameters $\beta(t)$, we also introduced a systematic relative variation according to $\Delta \beta(t)=K \beta_{\text {ref }}(t)$. In both cases the reduced sensibility to a parameter $\beta_{i}$ is approximated by the finite difference:

$$
S_{i} \equiv \beta_{i} \frac{\partial T}{\partial \beta_{i}} \approx\left(T_{\beta_{i}+\Delta \beta_{i}}-T_{\beta_{i}}\right) / K
$$

In the case of a time-dependent parameter $\beta(t)$ the application of a systematic relative variation has the disadvantage of minimizing the sensitivity to $\beta(t)$ when it comes close to 0 . We thus introduced another type of analysis, based on adding random variations to the nominal time evolution $\beta_{\text {ref }}(t)$ according to:

$$
\beta(t)=\beta_{r e f}(t)+K \bar{\beta}_{r e f}\left(2 u_{0,1}-1\right)
$$

where $\bar{\beta}_{\text {ref }}$ is the time average of $\beta_{\text {ref }}(t), K \ll<1$ and $u_{0,1}$ is the uniform distribution on the support $[0,1]$. A series of stochastic simulations has to be performed for a given $K$ value and the temperature scatter is then compared with the nominal temperature evolution. The reduced sensitivity to $\beta(t)$ is then given by the ratio of the standard deviation of the simulated temperature to the standard deviation of the uniform distribution of the considered parameter, i.e.:

$$
S_{i}(t)=\sigma_{T}(t) \sqrt{3} / K
$$

We plotted the reduced sensitivity to the thermal parameters of the three layers in figure 6 . The thermal behavior of any layer can be described with two parameters 
taken from the list $\left(R_{i}, c_{i}, b_{i}, \xi_{i}\right)$ where $R_{i}$ is thermal resistance $l_{i} / \lambda_{i}$ and $c_{i}$ is thermal capacity $\rho_{i} C_{i} l_{i}$. We started with the pair $\left(b_{i}, \xi_{i}\right)$ and noticed that for layers 2 and 3 these parameters are highly correlated. Choosing $\left(R_{i}, c_{i}\right)$ for these layers shows that temperature is mostly sensitive to $R_{i}$ and nearly not to $c_{i}$ (the sensitivity to the capacity of the third layer is not plotted because it is less than $10^{-3} \mathrm{~K}$ in absolute value). In figure 6 a reduced sensitivity of $1 K$ to a given parameter means that a deviation of $10 \%$ of this parameter yields a front temperature deviation of $0.1 \mathrm{~K}$. We can observe that the sensitivities to effusivity and square root of diffusion time of the first layer are decorrelated: they are opposite in sign and present a delay. Maximum absolute values of sensitivity are with respect to the front layer effusivity; this sensitivity is negative at day and positive at night; it reaches about $0.3 \mathrm{~K}$ per $10 \%$ effusivity variation. The sensitivity to the middle layer resistance $R_{2}$ is rather stable and it is a bit lower (in magnitude) than the sensitivity extremes with respect to $b_{1}$ and $\xi_{1}$. The sensitivity to the third layer resistance $R_{3}$ is still one order of magnitude lower.

We can see in figure 7-a the sensitivity of the front temperature to the convective coefficients and to the external and indoor air temperature. For the timevarying parameters, we present both the stochastic sensitivity as obtained through eq. (14) (curves with "stoc" label) and the sensitivity obtained after systematic flux alteration (curves with "syst" label). Regarding the external parameters, the air temperature is most critical to the results when the convective coefficient is high. For the two days presented here, the sensitivity to the air temperature reaches about $240 \mathrm{~K}$ for the systematic variation analysis, respectively $100 \mathrm{~K}$ for the stochastic analysis. It means that an error of $0.5 \%$ on the air temperature (in Kelvin), i.e. around $1.4 \mathrm{~K}$, yields an uncertainty of around $1.2 \mathrm{~K}$, resp. $0.5 \mathrm{~K}$, on the front surface temperature. The 
sensitivity to the internal air temperature is from 10 to 100 times lower. Similarly, the sensitivity is lower to the internal convection coefficient than the external convection coefficient.

The optical parameters and the incident flux densities define the radiative front excitation. In figure 7-b we plotted the reduced sensitivity (in absolute values) to the radiative parameters and to the radiative incident fluxes. Without surprise, the sensitivity to albedo and to a systematic variation of the incident solar flux are opposite and correlated in module. Sensitivity to a systematic variation of the solar heat flux is naturally maximum around midday: it reaches about $0.1 \mathrm{~K}$ for a $10 \%$ flux variation. It doesn't drop to 0 during night hours simply because the flux increase occurring during sunlit hours has also a positive impact on night temperatures. The sensitivity to albedo is homothetic to the sensitivity to incident solar flux by a ratio of about 3.6 , a value which can be explained by the actual value of albedo (i.e. 0.78 ). The sensitivity to the stochastic variations of the solar flux is lower: it is roughly $0.03 \mathrm{~K}$ for a $10 \%$ random flux variation. The fact that it is lower is mainly due to the inertial character of the wall: rapid variations of the solar flux (at the 15 min considered time step) are strongly attenuated with respect to a slow $24 h$ flux variation as considered in the systematic variation analysis. The noticeable result is that the front temperature is mostly sensitive to the infrared atmospheric flux (from 0.8 to $2.8 \mathrm{~K}$ per $10 \%$ systematic variation). As a consequence, this flux must be measured with a great care for expecting a good precision on the simulated temperature. The sensitivity to the external surface emissivity is from 3 to 10 times lower than the sensitivity to IR flux, in accordance to the fact that emissivity drives both the absorbed flux and the self-emitted flux (nominal emissivity was 0.947). 
As a conclusion on the sensitivity analysis we can state that for the present wall example the front temperature is mostly sensitive to the thermal and geometrical parameters of the first layer and to the thermal resistance of second layer, to the outdoor convective parameters (convective coefficient and air temperature), to the IR incoming flux and to emissivity. Therefore these parameters have to be measured with a high accuracy for getting the absolute temperature of the wall with a small error: for example the uncertainty has to be lower than about $2 \%$ for the IR incident flux, or $0.6 \mathrm{~K}$ for air temperature, to get an error lower than $0.5 \mathrm{~K}$. Incidentally, this analysis shows that the third layer and the indoor heat transfer coefficient would be extremely difficult to evaluate from the external surface temperature through a data inversion.

\section{Experimental campaign}

\section{Description}

The experimental measurement campaign BATIR took place in winter 2013 on the military airbase 701 at Salon-de-Provence, France. The thermal behaviour of two buildings was studied for a period of 13 days, from January $19^{\text {th }}$ to $31^{\text {st }} 2013$ (see figure 8). Two meteorological stations were used: one station (Campbell CR23X) was placed in an open area next to the runway and the other one (Campbell CR3000) was placed between the two buildings. Meteorological data were collected in order to estimate outdoor air temperature, wind velocity, global solar irradiance and IR irradiance. Air temperature inside the rooms was measured by probes (EL-USB-1-PRO) suspended close to back side of the façade wall of interest. The spectral reflectance of the participating surfaces was measured with an ASD spectroreflectometer in the [0.4-2.5 $\mu m]$ spectral domain and a SOC400T spectroreflectometer in the [2.9-13.3 $\mu \mathrm{m}]$ spectral domain. The albedo was calculated for each surface from the first spectral reflectance 
by weighting it with the solar spectral radiation provided by the atmosphere radiative transfer model MATISSE. Similarly the average IR emissivity was calculated from the measured IR spectral reflectance by weighting it with the Planck's law corresponding to a surface at $278 \mathrm{~K}$.

The thermography analysis was realised during two separate periods of 24 hours. Two 512x640 IR cameras were used: a band II camera (FLIR SC6000) and a band III camera (FLIR SC7000). The latter camera has been provided with a narrow filter. The halfheight spectral bands are respectively [3-5 $\mu \mathrm{m}]$ and [8.4-8.7 $\mu \mathrm{m}]$. The cameras were periodically aimed at an extended blackbody for drift correction and for establishing a relation between the output signal and the IR radiance in the respective bandwidths. For the first $24 h$ period thermographic measurements were performed by aiming the south façade of building LC3 from the north façade of building LC4. For the second period we performed the opposite. During this second period, five thermocouples and a fluxmeter were fixed on the north façade of building LC4 for getting independent values of the temperature and of the heat flux at particular locations of the wall. This wall is made of three layers, consisting of a reinforced concrete layer, an isolating PS layer and a BA13 plaster board. The respective layer thicknesses and thermal properties are given in table 2 . The effusivity of the $1^{\text {st }}$ and $3^{\text {rd }}$ layers was measured with a Thermicar sensor by implementing the asymmetric hot plane method [43]. Their conductivity and other missing thermal data were taken from literature.

Airborne thermography was also performed with a FLIR A325 microbolometer camera onboard of a motor glider. The camera was flown at about $40 \mathrm{~m} \cdot \mathrm{s}^{-1}$ speed and about 400 $m$ altitude. It was aiming at nadir. During the first thermography period, two flights were performed short after sunrise, at midday, and during the second period, three flights were performed short after sunrise, at midday and shortly before sunset. 


\section{Experimental validation of SUSHI}

The first experimental validation consisted in comparing our 1D thermal model results with the thermocouple measurements on the north facade of LC4 building. It was located far from the corners and from any thermal bridge so that the 1D hypothesis for heat flow in the wall was justified. The outside convective coefficient was calculated from wind speed by the empirical formula of Croiset:

$$
h_{e x}(t)=3.1+4.1 V^{0.605}
$$

with wind speed measured between the two buildings. Wind speed data were available from two meteorological stations, one in an open area, and the other between the buildings. The first data series was available for whole month and the second one only for the last day of interest (started at 10:00). One day of data was thus missing for allowing an analysis with a pseudo-period of $48 h$ as described before. Data from the first station were thus used for the missing day by applying a correction factor that was established by comparing the wind data recorded during the second, i.e. common, day. This extrapolation is justified by the fact that the wind direction didn't change during this couple of days. The outside air temperature was given by the remote station. The inside convective coefficient was arbitrarily fixed to $10 \mathrm{~W} \cdot \mathrm{m}^{-2} \cdot \mathrm{K}^{-1}$, with air temperature measured at an approximate distance of $5 \mathrm{~cm}$ from the surface. Let us mention here that only the net radiative solar flux was obtained from the temperature 3D field estimated by the SOLENE thermal code; the nested iterations aimed at updating the convective heat flux term and the radiative infrared flux term were thus performed by SUSHI (see figure 2). Temperature measured with a given thermocouple is compared with the simulated temperature of the corresponding facet. These thermograms are shown in figure 9. The uncertainty (at a confidence level of 95\%) of the thermocouple is $0.14^{\circ} \mathrm{C}$, 
and the day-average uncertainty of the simulated temperature is estimated at $2.2^{\circ} \mathrm{C}$, with maximal of $2.92^{\circ} \mathrm{C}$, as illustrated by the $+2 \sigma$ and $-2 \sigma$ curves in figure 9 . As the sensitivity study has shown a small systematic error on the external air temperature and on incident infrared radiation is dramatic for the precision of the simulated temperature. This is why the uncertainty of the simulated temperature was conservatively estimated by considering a systematic error (and not a "stochastic" error) of 5\% for all constant parameters, for external convective coefficient, for the incident solar and infrared radiation, of $0.5^{\circ} \mathrm{C}$ for external air temperature, and of $0.1^{\circ} \mathrm{C}$ to internal air temperature. Notwithstanding the relatively important value for the uncertainty of the simulated temperature, the RMS difference between the simulation and the measurements is only $0.33^{\circ} \mathrm{C}$ (with a maximum difference of $0.78^{\circ} \mathrm{C}$ ). The observed deviation between 03:00 and 09:00 may be explained by the presence of clouds at the sunrise. In the end, the thermal simulator provides satisfactory results; a significant effort has however to be undertaken for precisely evaluating the most influent environment parameters. The infrared cameras are then used for a spatial validation.

\section{Experimental validation of the full chain of simulation}

The façade of the building called "LC4" is used for the validation of the full chain of programs. The figure 10 presents three images of this façade: (a) is the infrared image measured by the camera SC7000 (in the [8.4-8.7 $\mu \mathrm{m}]$ spectral band), (b) is the simulated image obtained at the outlet of the simulation chain, (c) is the relative difference between the real and the simulated image and (d) is the vertical profile of radiance along the right side of the façade. The uncertainty (at a confidence level of $95 \%$ ) of the measured radiance is about $0.11 \mathrm{~W} \cdot \mathrm{m}^{-2} \cdot \mathrm{sr}^{-1}$. The main source of error for simulated radiance is the uncertainty of the transmitted-emitted radiance of the wall, which can be analytically computed. For an uncertainty of $1.1^{\circ} \mathrm{C}$ for the wall 
temperature and of 0.03 on the product emissivity-transmittance, the uncertainty of the simulated radiance is about $0.21 \mathrm{~W} \cdot \mathrm{m}^{-2} \cdot s r^{-1}$.

The image presented in fig. 10-left was recorded at 05:00 PM on January 29th. For the computation, a pseudo-period of two days was used to take into account the thermal dynamic of the scene. The scene was triangulated with about 10000 facets. Some areas with known thermal bridges were meshed more densely, namely the Tshape bridges corresponding to floor/façade junctions (they are clearly seen on the IR image in Figure 10-left). For convenience, the ground, the roof, the windows and the door contained few facets and we discarded the $45^{\circ} \mathrm{T}$-shape bridges corresponding stair/façade junction. At present, semi-transparency isn't modelled; this is why temperature and radiance of the windows aren't realistic. For the example presented here we didn't model the L-shape bridge corresponding to the building corners. The image of the relative difference shows that the radiances of 1D-wall parts are correctly estimated with a relative difference less than $2.5 \%$. One should nevertheless have in mind that relative RMS difference to about $12 \%$. Again, only with adapted meteorological sensor can we hope getting simulation results close to the real infrared sensor data. The effect of the thermal bridges at floor junctions on the radiance map is relatively well retrieved by the simulation despite the size of the facets used here.

Differences observed for the ground and the roof can be explained by the high "roughness" of these surfaces (they were considered flat in the 3D model). The difference reaches $9 \%$ at the soffit (the underside of the roof): the radiance of this part is higher than revealed by the simulation because the internal temperature can be higher than the measured temperature and the material is unknown. From this part some warm air could flow from the attic against the façade, which also could explain the difference just below the roof. 


\section{Conclusion}

In this work a numerical tool was developed for the simulation of the temperature field and the infrared rendering in an urban scene. The radiation energy budget at each facet of the modelled environment takes into account the multiples reflections of the incident solar flux (by SOLENE) and the IR radiative coupling between facets (by the new code SUSHI). The 1D response factors are calculated interactively by the quadrupole method whereas the $2 \mathrm{D}$ response factors are extracted form a database that was built from finite element calculation results. The model is based on a periodic approach. With real meteorological data, a pseudo-period of two days is sufficient for reducing the error induced but the periodicity hypothesis to satisfactory levels: less than $0.03 \mathrm{~K}$ for a typical wall and less than $0.8 K$ for the ground. The sensitivity study indicates the importance of the thermal properties of the first two layers of a wall, and the influence of measurement errors about external air temperature, emissivity and infrared incident flux. Validations of this tool were performed by comparing the output with thermocouples and infrared thermography measurements obtained during the experimental campaign BATIR. The final results show relatively little difference between measured and simulated radiance for the wall and the considered thermal bridges. This should not hide the fact that when combining all input uncertainties, the simulated radiance uncertainty may be significant, $10 \%$ and more, highlighting the requirement for a precise monitoring of the atmospheric thermal and radiative contribution.

Higher differences are observed for the roof (because of the geometry of the tiles) and the ground (because of its roughness) and at some locations for which boundary conditions were not well known (soffit and crawl space level). Further studies will be performed for analysing the airborne data. 
Similar geometrical computations are made by SOLENE and by MOHICANS for solar interactions in the scene. The next step will thus be to unify there computations and to use a unique module for the form factor matrix evaluation. In the future, the adding of a semi-transparent material model in SUSHI will enable us to consider more general situations with glazing surfaces and vegetation.

\section{Acknowledgements}

The authors thank PACA Region for its financial support, the laboratory CERMA for the provision of SOLENE software, the laboratory IUSTI for the provision of the IR MWIR camera and the ONERA staff who participated to the measurement campaign BATIR, in particular M. P.-Y. Foucher for his measurements of spectral reflectance. 


\section{REFERENCES}

[1] Lagouarde J-P, Hénon A, Irvine M, Voogt J, Pigeon G, Moreau P, Masson V, Mestayer P. Experimental characterization and modeling of the nighttime directional anisotropy of thermal infrared measurements over au urban area: case of study of Toulouse (France). Rem. Sens. Env. 2012;117:19-33.

[2] Asdrubali F, Baldinelli G, Bianchi F. A quantitative methodology to evaluate thermal bridges in buildings. Appl. En. 2012;97:365-373

[3] Kylili A, Fokaides P A, Christou P, Kalogirou S A. Infrared thermography (IRT) applications for building diagnostics: A review. Appl. En. 2014;134:531-549.

[4] Martín Ocaña S, Cañas Guerrero I, González Requena I. Thermographic survey of two rural buildings in Spain. En. Build. 2004;36:515-523.

[5] Oltra-Carrió R, Cubero-Castan M, Briottet X, Sobrino J A. Analysis of the Performance of the TES Algorithm Over Urban Areas. IEEE Trans. Geo. Rem. Sens. 2014:52;6989-6998.

[6] Datcu S, Ibos L, Candau Y, Matteï S. Improvement of building wall surface temperature measurements by infrared thermography. Infr. Phys. Tech. 2005;46:451-467.

[7] Chaffar K, Chauchois A, Defer D, Zalewski L. Thermal characterization of homogeneous walls using inverse method. En. Build. 2014;78:248-255.

[8] Avdelidis N P, Moropoulou A. Emissivity considerations in building thermography. En. Build. 2003;35:663-667.

[9] Albatici R, Tonelli A M. Infrared thermovision technique for the assessment of thermal transmittance value of opaque building elements on site. En. Build., 2010;42:2177-2183.

[10] Monchau J P, Ibos L, Feuillet V. Diagnosis of insulated building walls using passive infrared thermography and numerical simulations. EWSHM-7th Europ. Workshop Struct. Health Monitoring. 2014.

[11] Hénon A, Mestayer PG, Groleau D, Voogt J. High resolution thermo-radiative modeling of an urban fragment in Marseilles city center during the UBL-ESCOMPTE campaign. Build Env. 2011;46:1747-1764.

[12] Vavilov V. How accurate is the IR thermographic evaluation of heat losses from buildings? QIRT Journal. 2010;7:255-258.

[13] Zalewski L, Lassue S, Rousse D, Boukhalfa K. Experimental and numerical characterization of thermal bridges in prefabricated building walls. En. Conv. Manag. 2010;51:2869-2877.

[14] Masson V. A physically-based scheme for the urban energy balance in atmospheric models. Bound-Layer Meteor. 2000;94:357-397.

[15] Soux A, Voogt JA, Oke TR. A model to calculate what a remote sensor 'sees' of an urban surface, Bound-Layer Meteor. 2004;111:109-132.

[16] Kastendeuch PP, Najjar G. Simulation and validation of radiative transfers in urbanized areas. Sol Energy, 2009;83:333341.

[17] Asawa T, Hoyano A, Nakaohkubo K, Thermal design tool outdoor spaces based on heat balance simulation using a 3DCAD system. Build Env. 2008;43:2112-2123.

[18] Krayenhoff ES, Voogt JA. A microscale three-dimensional urban energy balance model for studying surface temperatures. Bound-Layer Meteor. 2007;123:433-461.

[19] Dupont S, Mestayer PG. Parameterization of the urban energy budget with the submesoscale soil model. J Appl Meteor Clim. 2006;45:1744-1765.

[20] Yang X, Li Y. Development of a 3D urban energy model for predicting and understanding surface temperature distribution. Bound-Layer Meteor. 2013;149:303-321.

[21] Miguet F, Groleau D. A daylight simulation tool for urban and architectural spaces - application to transmitted direct and diffuse light through glazing. Build Env. 2002;37:833-843.

[22] Cohen MF, Chen SE, Wallace JR, Greenberg DP. A progressive refinement approach to fast radiosity image generation. Comp Graph, 1988;22:75-84.

[23] Idczak M, Groleau D, Mestayer P, Rosant JM, Sini JF. An application of the thermo-radiative model SOLENE for the evaluation of street canyon energy balance. Build Env. 2010;45:1262-1275.

[24] Berk A, Anderson GP, Bernstein LS, Acharya PK, Dothe H, Matthew MW, Adler Golden SM, Chetwynd JH, Richtsmeier SC, Pukall B, Allred CL, Jeong LS, Hoke ML. MODTRAN4 radiative transfer modeling for atmospheric correction. Proc. SPIE 3756; 1999.

[25] Labarre L, Caillault K, Fauqueux S, Malherbe C, Roblin A, Rosier B, Simoneau P, An overview of MATISSE-v2.0. In: Rem Sens. Inter S Opt Photon; 2010.

[26] Gastellu-Etchegorry JP. 3D modeling of satellite spectral images, radiation budget and energy budget of urban landscapes. Meteor Atm Phys. 2008;102:187-207.

[27] Fontanilles G, Briottet X, Fabre S, Trémas T. Thermal infrared radiance simulation with aggregation modeling TITAN an infrared radiative transfer model for heterogeneous 3D surface - application over urban areas. Appl Opt. 2008;47:57995810 .

[28] Thomas C, Doz S, Briottet X, Lachérade S. AMARTISv2: 3D radiative transfer code in the [0.4; $2.5 \mu \mathrm{m}]$ spectral domain dedicated to urban areas. Rem Sens. 2011;3:1914-1942.

[29] Perez R, Seals R, Michalsky J. All weather model for sky luminance distribution - preliminary configuration and validation. Sol Energy. 1993;50:235-245.

[30] Bouyer J., Inard C., Musy M. Microclimatic coupling as a solution to improve building energ simulation in an urban context. En. Build. 2011;43:1549-1559.

[31] Gros A., Bozonnet E., Inard C. Cool materials impact at district scale - Coupling building energy and microclimate models. Sustain. Cities Soc. 2014;13:254-266.

[32] Palyvos J.A. A survey of wind convection coefficient correlations for building envelope energy systems modeling. Appl. Therm. Eng. 2008;28:801-808.

[33] Krapez JC, Tadé V, Barillot P, Miesch C. Modélisation analytique de la variabilité spatiale et temporelle de la température de sols nus naturels, Congrès SFT 2004, Presqu'île de Giens (France).

[34] Maillet D, André S, Batsale JC, Degiovanni A, Moyne C. Thermal quadrupoles: solving the heat equation through integral transforms. Wiley; 2000.

[35] Tadeu A, Simoes I, Simoes N, Prata J. Simulation of dynamic linear thermal bridges using a boundary element method model in the frequency domain. En. Build. 2011;43:3685-3695.

[36] Clarke J-A. Energy simulation in building design, $2^{\text {nd }}$ ed. Butterworth-Heineman, Oxfrod, 2001. 
[37] Déqué F, Ollivier F, Roux J J. Effect of 2D modelling of thermal bridges on the energy performance of buildings Numerical application on the Matisse apartment. En. Build. 2001;33:583-587.

[38] Martin K, Erkoreka A, Flores I, Odriozola M, Sala J M. Problems in the calculation of thermal bridges in dynamic conditions. En. Build. 2011;43:529-535.

[39] Depecker P, Menezo C, Virgone S, Lepers S. Design of buildings shape and energetic consumption. Build. Env. 2001;36:627-635.

[40] Pailhes J, Pradere C, Battaglia JL, Toutain J, Kusiak A, Aregba AW, Batsale JC. Thermal quadrupole method with internal heat sources. Int J Therm Sc. 2012;53:49-55.

[41] Krapez JC, Dohou E. Three methods based on the thermal quadrupole approach for an improved computation of temperature and flux in multilayered materials with internal heat sources, Int J Therm Sc. 2014;81:38-51.

[42] Frigo M, Johnson S. The design and implementation of FFTW3. Proc IEEE. 2005;93:216-231. http://www.fftw.org.

[43] Krapez JC, Caractérisation thermique non intrusive au moyen d'un plan chaud et d'un fil chaud asymétriques, Congrès Français de Thermique, SFT 2007, Les Embiez, 29 mai-01 juin 2007, R. Martin L. Tadrist eds, Editions SFT, p. 897-90.

[44] D. Wyart, "Polystyrène expansé ou PSE", Techniques de l'Ingénieur, 2008.

[45] F. Kuznik, J. Virgone, J. Noel, Optimization of a phase change material wallboard for building use, Appl. Therm. Eng., $2008 \cdot 28: 1291-1298$

[46] C. Giaconia, A. Orioli, On the reliability of ASHRAE conduction transfer function coefficients of walls, Appl. Therm. Eng., 2000;20:21-47. 
Table 1. Main existing thermo-radiative urban models.

Table 2. Wall characteristics.Figure 1. Flow chart of the simulator

Figure 2. Flow diagram of the parameters/variables computed by SOLENE and by SUSHI

Figure 3. L-shaped (a) and T-shaped (b) thermal bridges. The two generic heat flow distributions are indicated by arrows for each case.

Figure 4. Radiative components computed by MOHICANS and contributing to the radiance at sensor level.

Figure 5. RMS error and maximum absolute error (Max) for surface temperature depending on the number of days considered for the pseudo-period in the case of a wall and a ground of effusivity 1000 SI or 2000 SI. The reference is obtained with a pseudoperiod of 12 days. (a) absolute error and (b) relative error to the min/max temperature contrast obtained for current day.

Figure 6. Relative sensitivity of external temperature to the thermal properties of the three-layer wall $\left(b_{i}, \xi_{i}, R_{i}\right.$ and $c_{i}$ are the effusivity, the square root of diffusion time, the thermal resistance and the thermal capacity of layer i).

Figure 7. Same with respect to the convective parameters (a) and to the radiative parameters (b).

Figure 8. Analysed scene during the BATIR campaign (a) and airborne IR image (b).

Figure 9. Comparison between the temperature simulated by SUSHI and the temperature measured by a thermocouple on the façade of LC4 building.

Figure 10. Comparison between the radiance measured by thermography (a) and the radiance simulated by SOLENE/SUSHI/MOHICANS (b). Radiance contrast for the image (c) and radiance profile along the façade of LC4 building (d). 
Table 1. Main existing thermo-radiative urban models.

\begin{tabular}{|c|c|c|c|c|c|}
\hline $\begin{array}{l}\text { Model: autors, } \\
\text { (NAME), year }\end{array}$ & $\begin{array}{l}\text { Groleau et al. } \\
\text { SOLENE [21] (2003) }\end{array}$ & $\begin{array}{l}\text { Krayenhoff, Voogt } \\
\text { TUF-3D [18] (2007) }\end{array}$ & $\begin{array}{l}\text { Asawa, Hoyano } \\
\text { [17] (2008) }\end{array}$ & $\begin{array}{l}\text { Kastendeuch, Najjar } \\
\text { [16] (2008) }\end{array}$ & $\begin{array}{l}\text { Yang, Li } \\
\text { MUST [20] (2013) }\end{array}$ \\
\hline 3D scene & From SketchUp & $\begin{array}{l}\text { 3D cells organized in } \\
\text { cluster geometry }\end{array}$ & $\begin{array}{l}\text { 3D-CAD } \\
\text { with trees }\end{array}$ & $3 \mathrm{D}$ & $\begin{array}{l}\text { 3D cells organized } \\
\text { in cluster geometry }\end{array}$ \\
\hline Direct solar & $\begin{array}{l}\text { Measure or Perrin de } \\
\text { Brichambaut model }\end{array}$ & Iqbal's model (83) & Bouguer's law & $\begin{array}{l}\text { Measure + position } \\
\text { by Reda Afshin }\end{array}$ & Bouguer's law \\
\hline Diffuse solar & $\begin{array}{l}\text { Measure + "all } \\
\text { weather" Perez sky }\end{array}$ & Iqbal's model (83) & Nagata's formula & $\begin{array}{l}\text { Measure + "all } \\
\text { weather" Perez sky }\end{array}$ & Berlage's relation \\
\hline $\begin{array}{l}\text { Atmospheric } \\
\text { radiation }\end{array}$ & $\begin{array}{l}\text { Measure + sky view } \\
\text { factor }\end{array}$ & Prata's formula (96) & Brunt's formula & $\begin{array}{l}\text { Measure }+ \\
\text { homogeneous }\end{array}$ & $\begin{array}{l}\text { Model of Berdahl } \\
\text { and Martin (84) }\end{array}$ \\
\hline Shape factor & $\begin{array}{l}\text { By subdivision in } \\
\text { triangular facets }\end{array}$ & $\begin{array}{l}\text { Exact plane parallel } \\
\text { analytical equation }\end{array}$ & $\begin{array}{l}\text { Deduced from sky } \\
\text { view factor }\end{array}$ & Pianykh's method & $\begin{array}{l}\text { By a method similar } \\
\text { to Monte Carlo }\end{array}$ \\
\hline $\begin{array}{l}\text { Multiple } \\
\text { reflections VNIR }\end{array}$ & $\begin{array}{l}\text { Progressive } \\
\text { refinement }\end{array}$ & $\begin{array}{l}\text { Two reflections } \\
\text { minimum }\end{array}$ & One & $\begin{array}{l}\text { Progressive } \\
\text { refinement }\end{array}$ & Gebhart factor \\
\hline $\begin{array}{l}\text { Multiple } \\
\text { reflections IR }\end{array}$ & $\begin{array}{l}\text { Progressive } \\
\text { refinement (not with } \\
\text { sky) }\end{array}$ & $\begin{array}{l}\text { Isotropique sky } \\
\text { radiance }\end{array}$ & $\begin{array}{l}\mathrm{CN}+\text { other surface } \\
\text { at } \mathrm{T}_{\text {air }}\end{array}$ & $\begin{array}{l}\text { Progressive } \\
\text { refinement (not with } \\
\text { sky) }\end{array}$ & Gebhart factor \\
\hline Sensible heat flow & Imposed $\mathrm{h}$ & $\begin{array}{l}\text { Function of surface } \\
\text { roughness and } \\
\text { effective wind speed }\end{array}$ & Jürges's formula & $\mathrm{h}$ by Ito (78) & $\begin{array}{l}\text { Function of surface } \\
\text { roughness and } \\
\text { effective wind speed }\end{array}$ \\
\hline $\begin{array}{l}\text { Wall thermal } \\
\text { model }\end{array}$ & Nodal (5 nodes) & $\begin{array}{l}\text { Finite differences }+ \\
\text { iterative process with } \\
\text { IR radiation }\end{array}$ & $\begin{array}{l}\text { Finite differences ( } 5 \\
\text { days) }\end{array}$ & $\begin{array}{l}\text { Finite differences }+ \\
\text { iterative process with } \\
\text { IR radiation }\end{array}$ & Finite differences \\
\hline Main limitation & $\begin{array}{l}\text { Limited number of } \\
\text { nodes }\end{array}$ & $\begin{array}{l}\text { Simplified geometry } \\
\text { (3D Cartesian) }\end{array}$ & $\begin{array}{l}\text { Simplified reflection } \\
\text { of VNIR and IR } \\
\text { fluxes }\end{array}$ & $\begin{array}{l}\text { 3D scene and wall } \\
\text { discretization }\end{array}$ & $\begin{array}{l}\text { Simplified geometry } \\
\text { (3D Cartesian) }\end{array}$ \\
\hline
\end{tabular}

Table 2. Wall characteristics.

\begin{tabular}{lccccc}
\hline Layer & $\begin{array}{c}e \\
(\mathrm{~m})\end{array}$ & $\begin{array}{c}k \\
\left(\mathrm{~W} \cdot \mathrm{m}^{-1} \cdot \mathrm{K}^{-1}\right)\end{array}$ & $\begin{array}{c}\rho \cdot C_{p} \\
\left(\mathrm{~kJ} \cdot \mathrm{m}^{-3} \cdot \mathrm{K}^{-1}\right)\end{array}$ & $\left(\mathrm{J} \cdot \mathrm{s}^{-1 / 2} \cdot \mathrm{m}^{-2} \cdot \mathrm{K}^{-1}\right)$ & $\begin{array}{c}\xi \\
\left(\mathrm{s}^{1 / 2}\right)\end{array}$ \\
\hline Reinforced concrete & 0.17 & $1.8[46]$ & 2112 & $1950^{(1)}$ & 184.1 \\
EPS & 0.027 & $0.037[44]$ & $21[44]$ & 27.9 & 20.3 \\
Plaster (BA13) & 0.013 & 0.31 & $825[45]$ & $504^{(1)}$ & 21.3 \\
\hline (1) &
\end{tabular}

(1) Values given by on-site measurements 


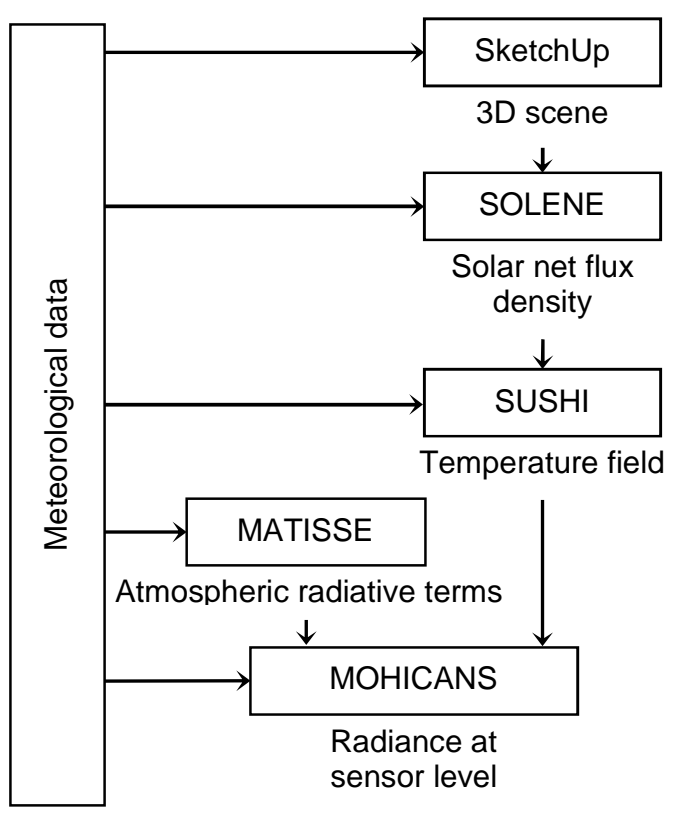

Figure 1. Flow chart of the simulator

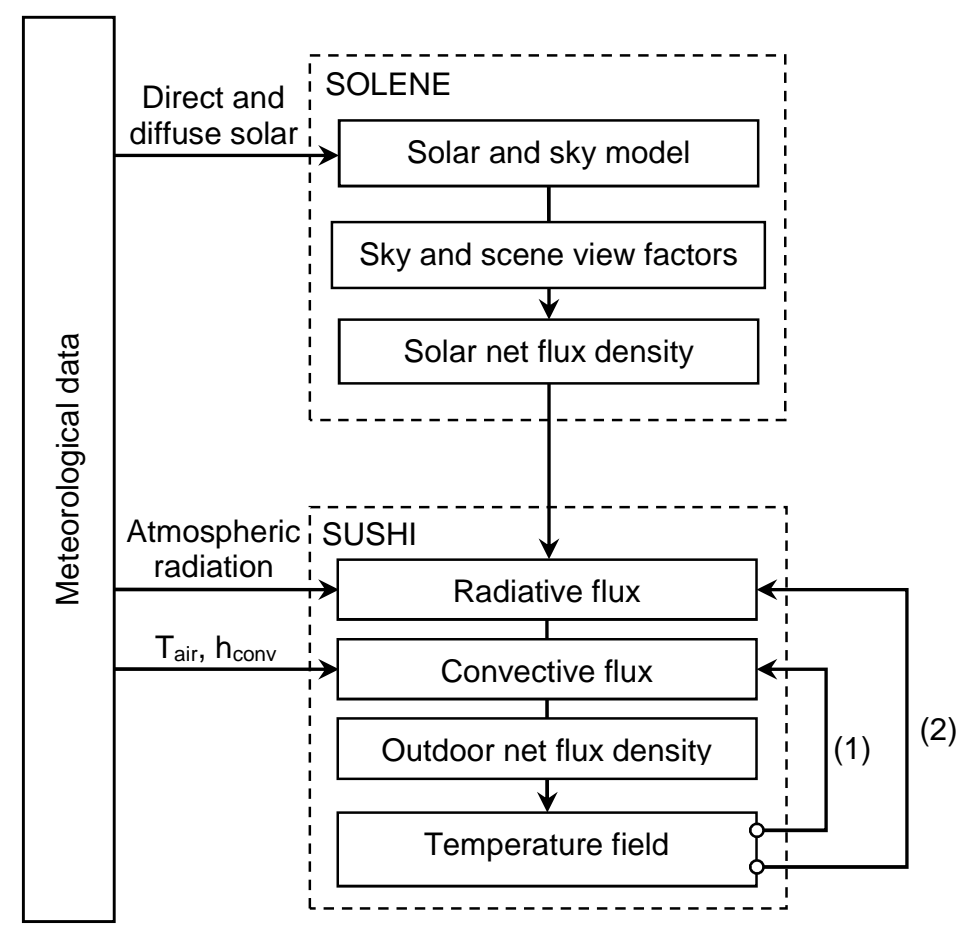

Figure 2. Flow diagram of the parameters/variables computed by SOLENE and by SUSHI 

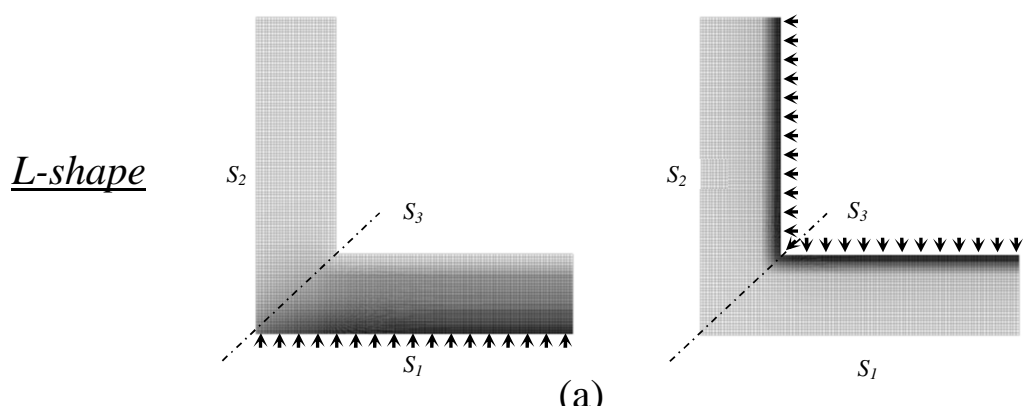

(a)

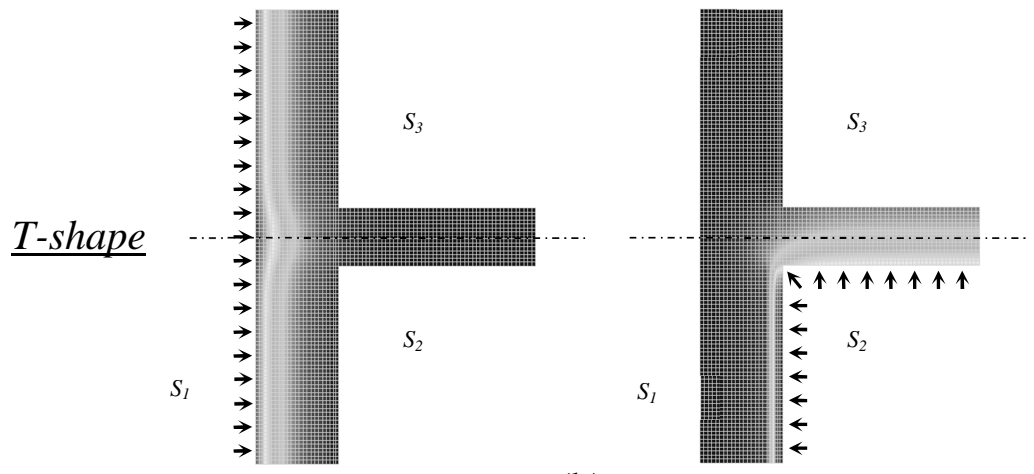

(b)

Figure 3. L-shaped (a) and T-shaped (b) thermal bridges. The two generic heat flow distributions are indicated by arrows for each case.

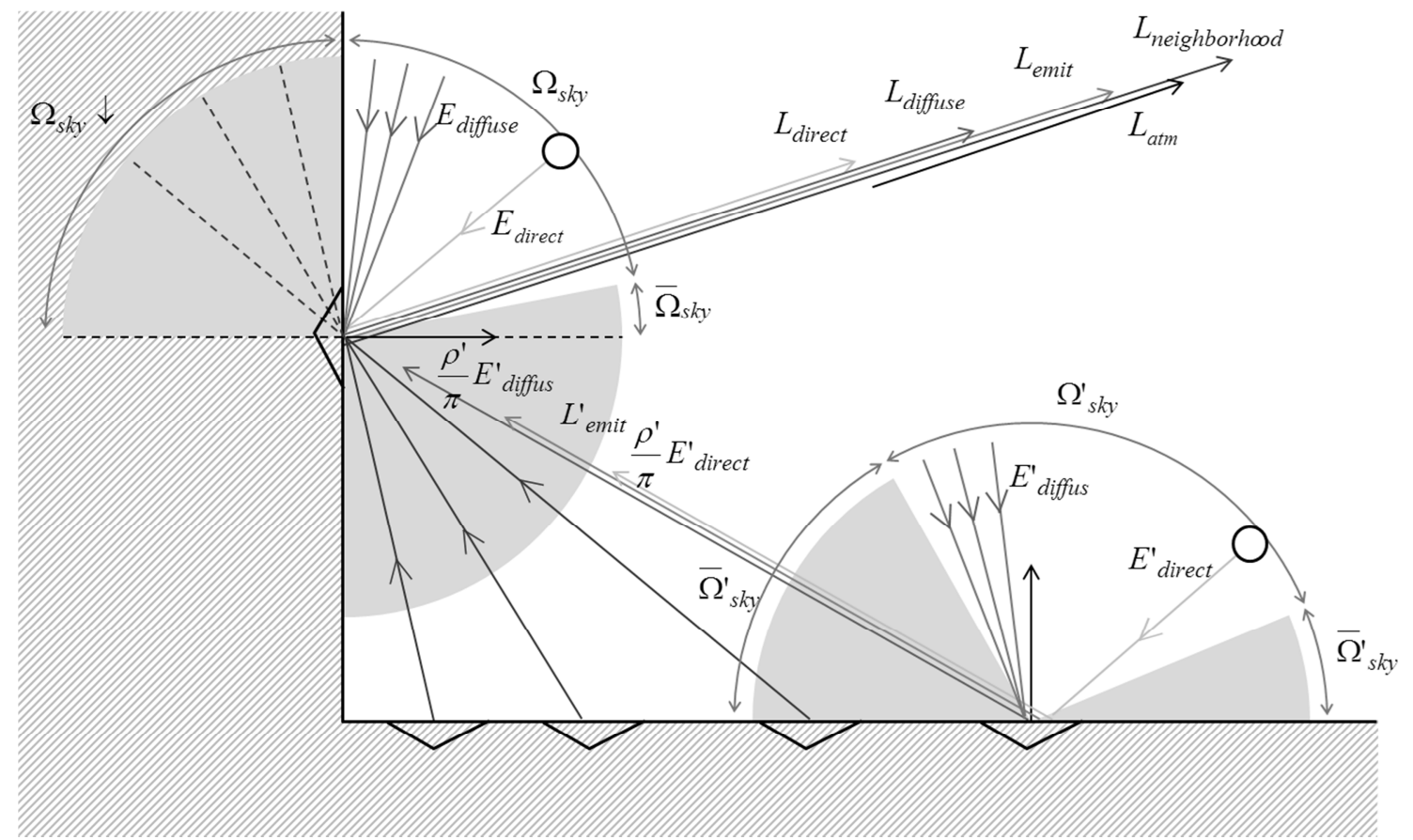

Figure 4. Radiative components computed by MOHICANS and contributing to the radiance at sensor level. 


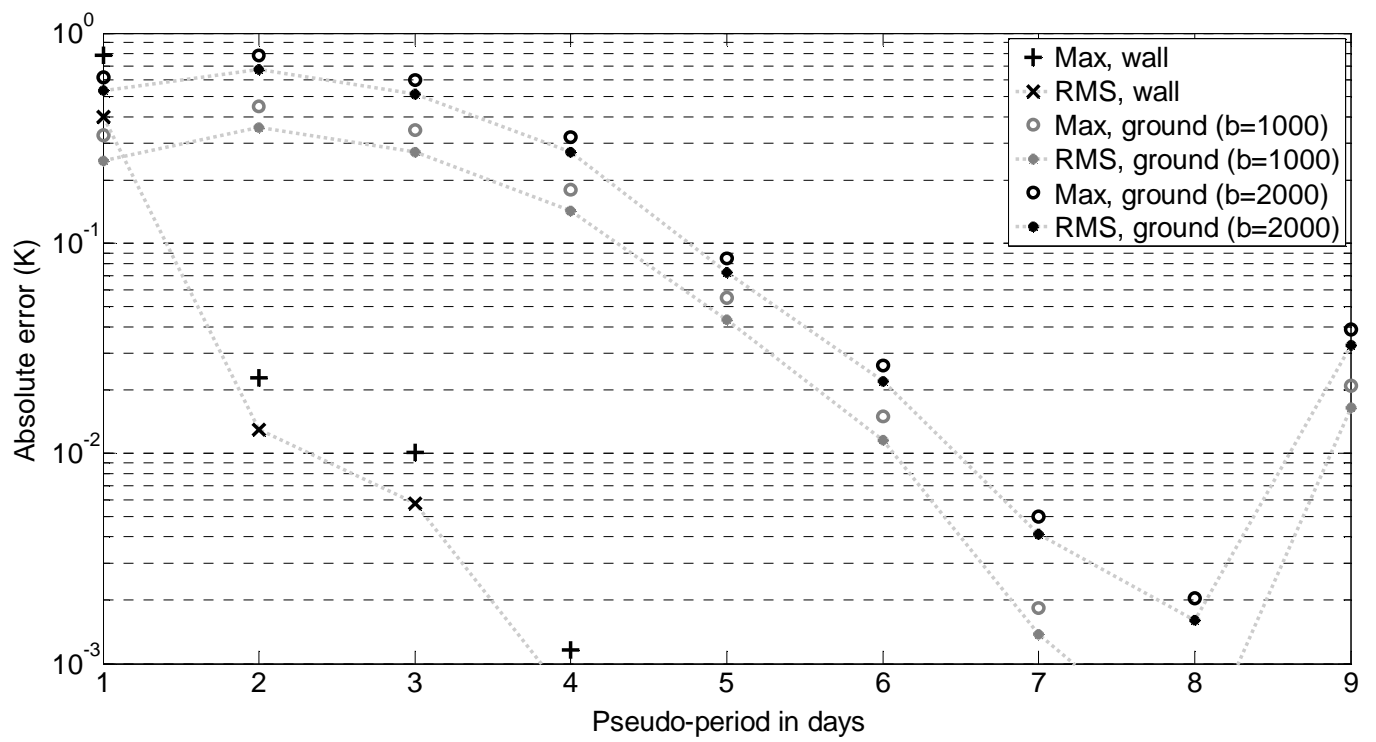

(a)

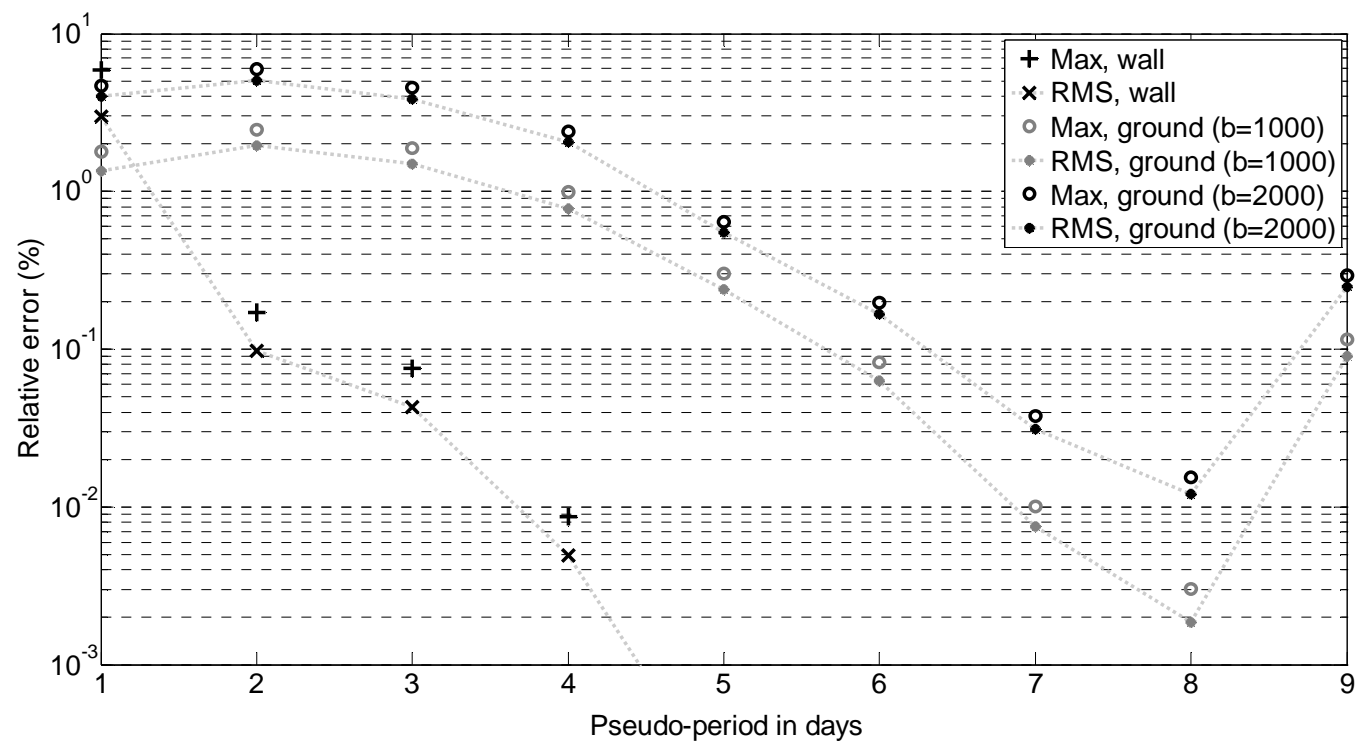

(b)

Figure 5. RMS error and maximum absolute error (Max) for surface temperature depending on the number of days considered for the pseudo-period in the case of a wall and a ground of effusivity 1000 SI or 2000 SI. The reference is obtained with a pseudoperiod of 12 days. (a) absolute error and (b) relative error to the $\min / \mathrm{max}$ temperature contrast obtained for current day. 


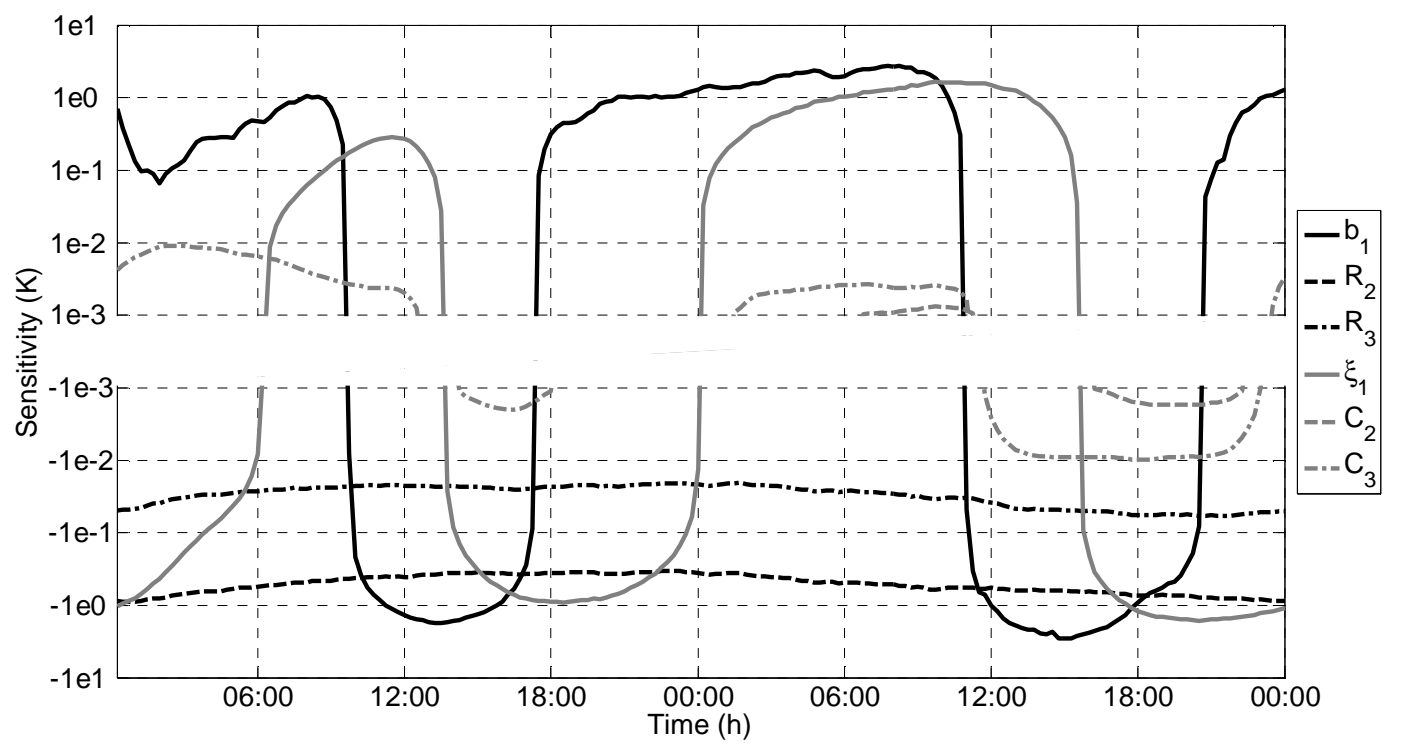

Figure 6. Relative sensitivity of external temperature to the thermal properties of the three-layer wall $\left(b_{i}, \xi_{i}, R_{i}\right.$ and $c_{i}$ are the effusivity, the square root of diffusion time, the thermal resistance and the thermal capacity of layer i).

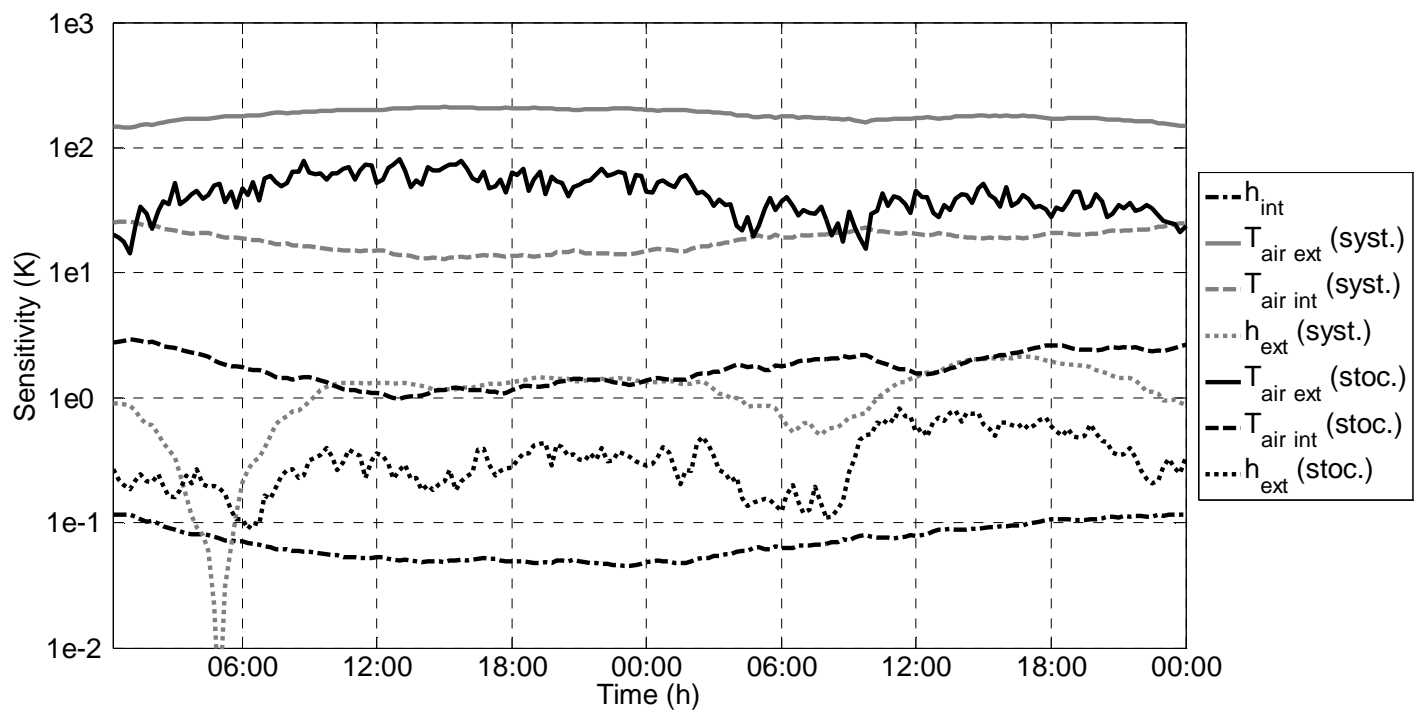

(a) 


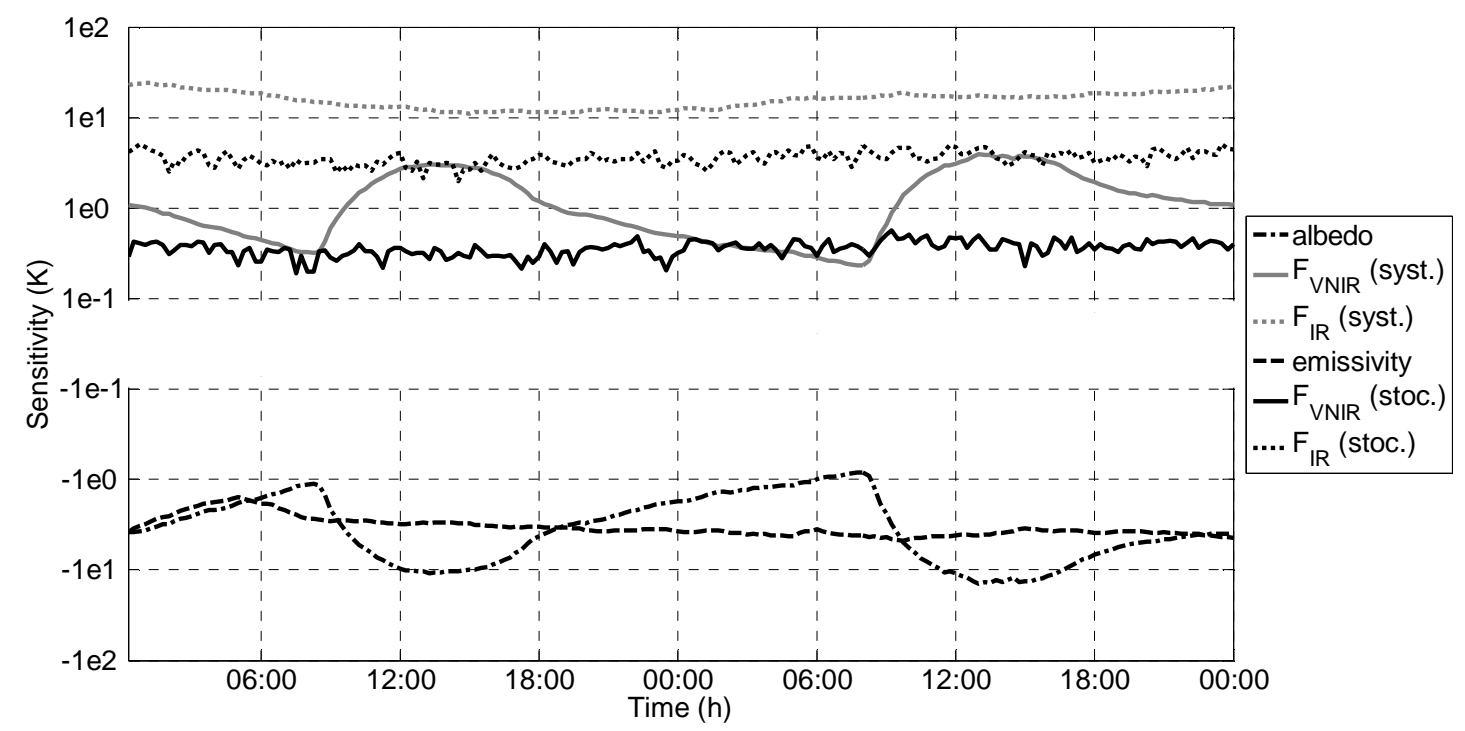

(b)

Figure 7. Same with respect to the convective parameters (a) and to the radiative parameters (b).

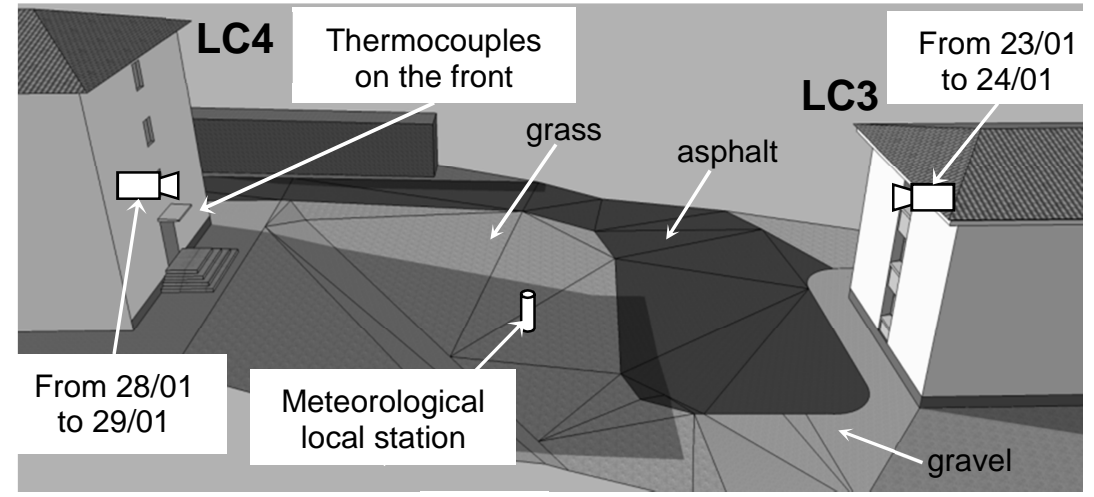

(a)

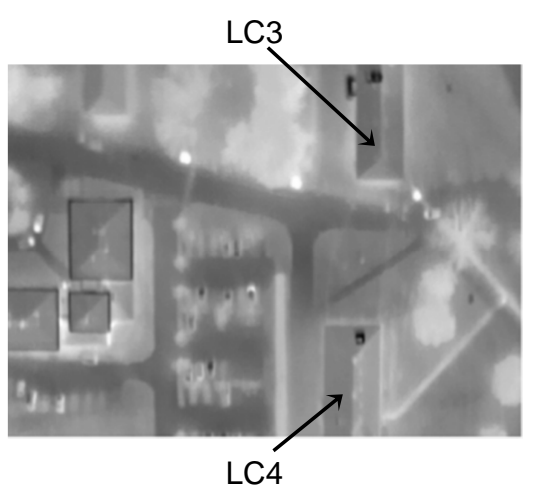

(b)

Figure 8. Analysed scene during the BATIR campaign (a) and airborne IR image (b). 


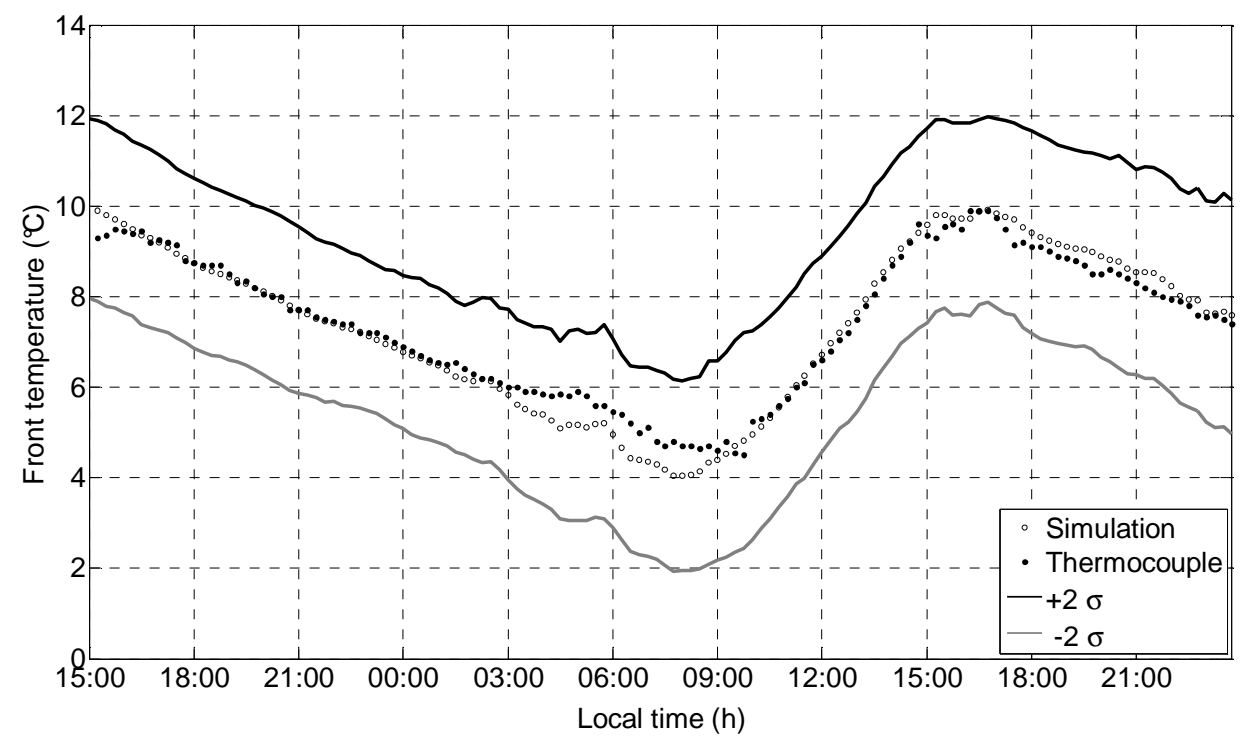

Figure 9. Comparison between the temperature simulated by SUSHI and the temperature measured by thermocouple on the façade of LC4 building.

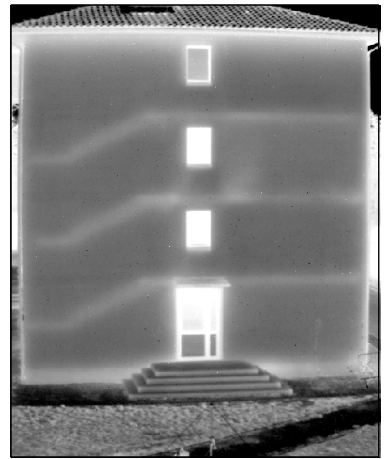

(a)

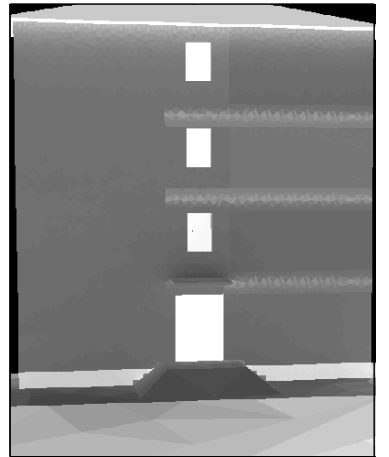

(b)

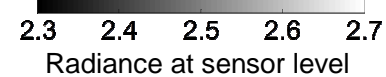

Radiance at sensor level (W. $\mathrm{m}^{-2} \cdot \mathrm{sr}^{-1}$ )

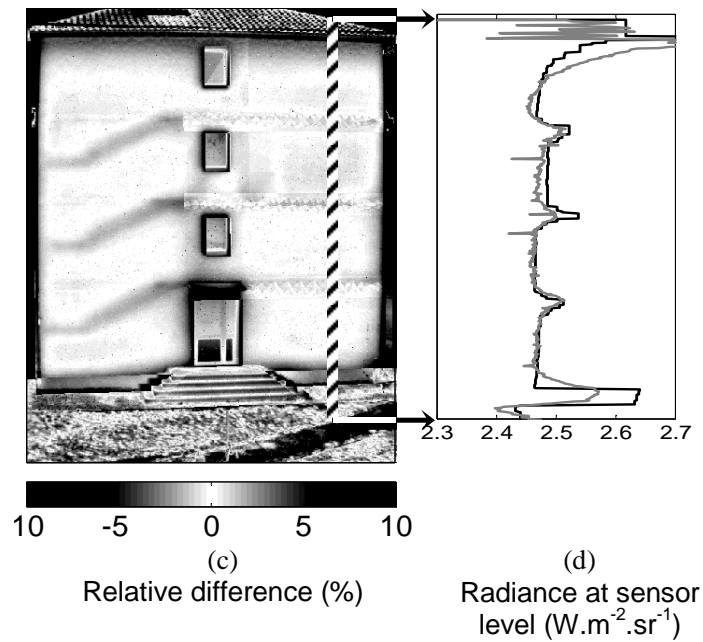

Figure 10. Comparison between the radiance measured by thermography (a) and the radiance simulated by SOLENE/SUSHI/MOHICANS (b). Radiance contrast for the image (c) and radiance profile along the façade of LC4 building (d). 